\title{
Disruption Risk Management in Reverse Supply Chain by Using System Dynamics
}

\author{
Qiao-Lun GU ${ }^{1,2, a,{ }^{*}}$, George TAGARAS ${ }^{2, b}$, Tie-Gang GAO ${ }^{3, c}$ \\ ${ }^{1}$ School of Economics and Management, Tianjin University of Technology and Education, Tianjin, \\ 300222, China \\ ${ }^{2}$ Department of Mechanical Engineering, Aristotle University of Thessaloniki, Thessaloniki, Greece \\ ${ }^{3}$ College of Software, Nankai University, Tianjin, 300071, China \\ atjguqiaolun@sohu.com, btagaras@auth.gr, ' gaotiegang@nankai.edu.cn \\ *Corresponding author
}

Keywords: Disruption risk, Evaluation, Reverse supply chain, System dynamics.

\begin{abstract}
We examine reverse supply chains consisting of three members (collector, disassembly center, remanufacturer) and subject to four different types of supply disruption, each with distinct impact on the members of the chain. Using system dynamics methodology, we focus on the quantitative method of disruption risk evaluation by simulation analysis of the impacts of each supply disruption on the Mean profits of the various supply chain member. We introduce the concept of "Impact Degree" to quantify the effects of the supply disruptions. We compare the Impact Degrees of four different types of supply disruption via an illustrative example, and we find that a supply disruption which occurs between end-consumers and the collector has the highest Impact Degree on the collector, the disassembly center and the remanufacturer. This novel quantitative method of disruption risk evaluation can help to investigate the highest risk disruption in all kinds of supply chain not only in reverse supply chain.
\end{abstract}

\section{Introduction}

We consider a reverse supply chain comprising three members: collector, disassembly center and remanufacturer. The collector collects the used-products from the end-consumers and sells them to the disassembly center. The disassembly center reprocesses the used-products and sells the key remanufactured part to the remanufacturer. The remanufacturer produces remanufactured products, which contain the key remanufactured part and sells them to the consumer market.

The operation of any reverse supply chain is often subject to supply disruptions, which generally have low probabilities of occurrence but potentially severe adverse impacts on the supply chain members. The supply disruptions can be categorized into four types (I, II, III, IV) according to their "location" which are shown in Figure 1. With regard to the four supply disruptions, the following questions need to be answered: What are the profit changes of the reverse supply chain members when each supply disruption occurs and how do they depend on the length of the disruption period? Which supply disruption has the strongest impacts on the reverse supply chain members?

Motivated by these questions, we simulate and analyze the impacts of the four supply disruptions on the Mean profits of the three supply chain members, and introduce the concept of "Impact Degree" to quantify and compare the impacts of the four supply disruptions. The main tool in our study is the system dynamics methodology, which allows us to obtain specific numerical results and useful managerial insights.

\section{Literature Review}

In the past few years SD has started being used as a tool of disruption management in supply chains. Wilson (2007) investigates the effect of a transportation disruption on supply chain performance using $\mathrm{SD}$. The transportation disruption arises when the material flow is interrupted between two echelons in a 
supply chain, temporarily stopping the transit of these goods. The author finds that the greatest impact occurs when transportation is disrupted between the tier 1 supplier and the warehouse. Yang (2008) analyzed the impact of stock disruptions on supply chain performance by means of SD. Ankit (2010) investigates the impact of supply disruption between any two players on the performance of a multiplayer supply chain system comprising Retailer, Wholesaler, Distributor and Factory. Chen et al. (2011) employ SD to construct a traditional supply chain model, a pipeline-inventory-control (PIC) supply chain model and a vendor-managed-inventory (VMI) supply chain model in order to study the long-run effect of disruptions on supply chain performance. Huang et al. (2012) build two models for a supply chain under two circumstances of supply disruptions by using the methodology of system dynamics. Lorentz \& Hilmola (2012) introduce a continuous simulation model that is based on a Bayesian robot decision-maker. Using the system dynamics approach, they illustrate the process of evaluating competing hypotheses of functional vs dysfunctional supply chain design in a disruption scenario. Ma et al. (2012) develop a new approach to measure supply chain disruption risks by combining system dynamics and ARIMA-intervention-analysis method. They propose a system dynamics model to depict the supply chain system's behavior under transportation disruption risk.

The previous studies that are most closely related to the present paper are those of Gu \& Gao (2011) and $\mathrm{Gu} \& \mathrm{Gao}$ (2012). The former develops a system dynamics model of the reverse supply chain capable of evaluating inventories, service levels, and profits with and without RFID-EPC. However, that paper does not consider the possibility of supply disruptions. The latter (Gu \& Gao 2012) extends the stock-flow diagram of the former so as to include the case of supply disruption and selects a strategy to ensure that the remanufacturing operation will remain profitable even when the supply disruption lasts for a long time. The present paper extends the previous studies by examining and comparing four types of supply disruption in the reverse supply chain.

\section{Model Development}

\section{Four supply disruptions of reverse supply chain}

Figure 1 shows a reverse supply chain with three members and four possible supply disruptions. Following the earlier works of $\mathrm{Gu} \& \mathrm{Gao}(2011,2012)$, the amount of collected used products of this reverse supply chain is stochastic and RFID/EPC may be used to reduce this uncertainty. The collector bears the cost of evaluating the state of used-products waiting for collection by using RFID/EPC.

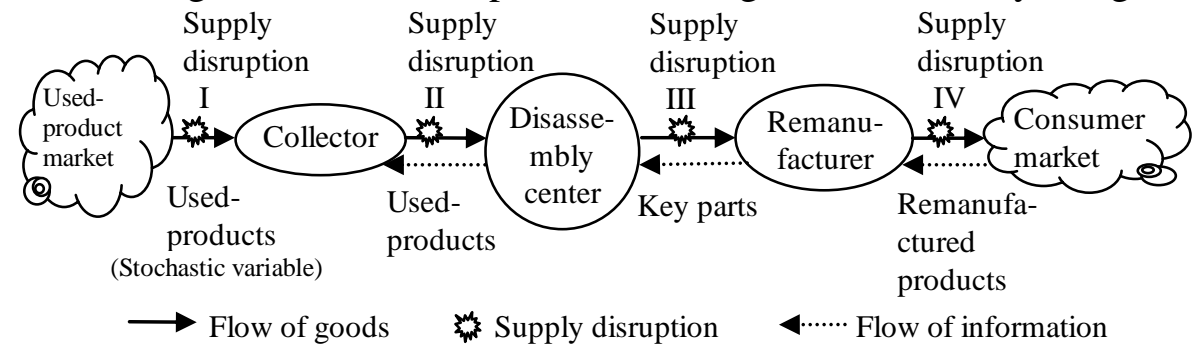

Fig. 1 Four supply disruptions of reverse supply chain

The supply disruptions refer to a special kind of supply chain risks. A disruption here is defined as an event that completely interrupts the material flow in the supply chain, resulting in an abrupt cessation of the movement of goods. It can be caused by a natural disaster, labor dispute, dependence on a single supplier, supplier bankruptcy, terrorism, war, political instability (Wilson 2007). Such a disruption may halt the supply chain operations for a long time if no precautionary measures are taken to accelerate the recovery of the affected system (Sheffi \& Rice 2005; Hendricks \& Singhal2005). Different durations of disruption will obviously have different effect on the supply chain members.

When supply disruption of type I occurs in the reverse supply chain of Figure 1, there will be no supply of used-products from used-product market to collector. In other words, the collector cannot collect any used-products. When supply disruption II hits the reverse supply chain, the disassembly center cannot get used-products from the collector. Supply disruption III will result in discontinuation of key parts transport from the disassembly center to the remanufacturer. If the reverse supply chain encounters supply disruption IV, no remanufactured products can be transported to the consumer market. 


\section{Stock-flow Diagram with Supply Disruptions}

The stock-flow diagram with supply disruption is an extension of the stock-flow diagram in Gu \& Gao (2011) and has been created using Vensim ${ }^{\circledR} 5.10$, a visual modeling tool that can be used to conceptualize, document, simulate, analyze, and optimize models of dynamic systems. Vensim provides a simple and flexible way of building simulation models from stock and flow diagrams that captures the model structure and the interrelationships among the variables. As an example, the stock-flow diagram with supply disruption II of the reverse supply chain under consideration is shown in Figure 2 . The variables and constants involved in stock-flow diagram with supply disruptions can be referenced in $\mathrm{Gu} \&$ Gao (2011) and Gu \& Gao (2012).

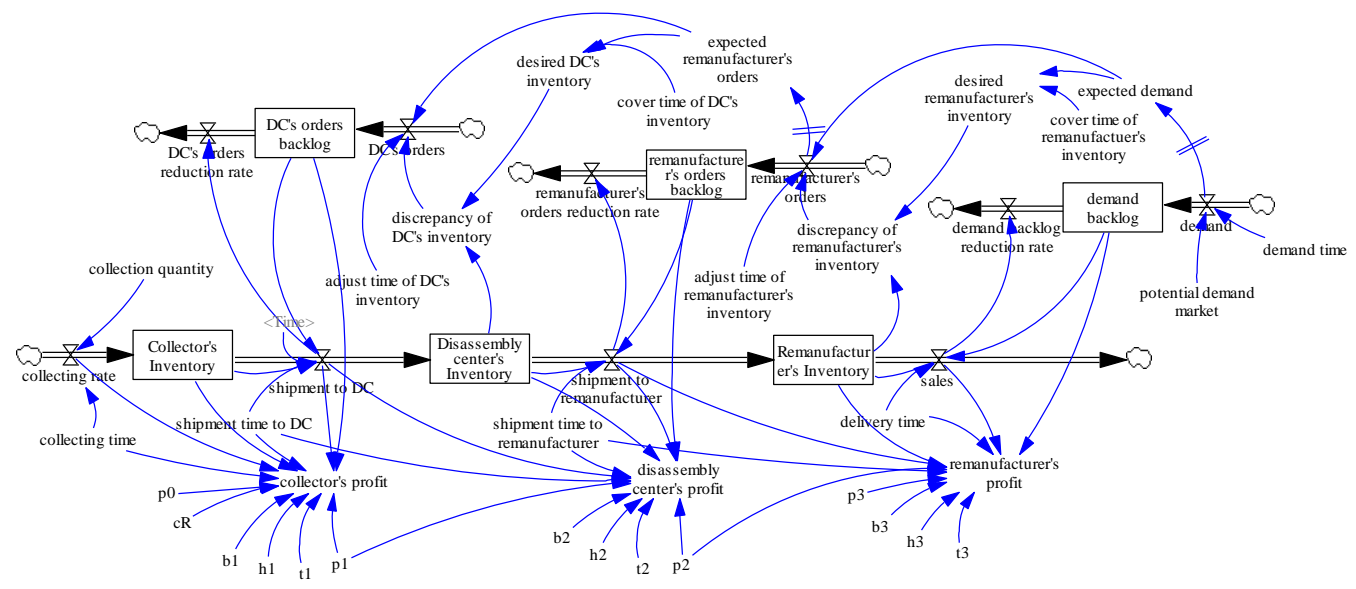

Fig. 2 Stock-flow diagram with supply disruption II

Table 1 Equations of four supply disruptions

\begin{tabular}{|c|c|}
\hline Supply disruption & Equations \\
\hline I & $\begin{array}{c}\text { collecting rate }=\text { if then else }(\text { Time }<=m, \text { collection quantity/collecting time, if then else }(\text { Time }>n, \\
\text { collection quantity/collecting time, } 0) \text {, }\end{array}$ \\
\hline II & $\begin{array}{c}\text { shipment to } D C=\text { if then else }(\text { Time }<=m, M I N(\text { Collector's Inventory, DC's orders backlog }) / \text { shipment } \\
\text { time to } D C \text {, if then else (Time }>n, M I N(\text { Collector's Inventory, DC's orders backlog }) / \text { shipment time to } \\
D C, 0))\end{array}$ \\
\hline III & $\begin{array}{c}\text { shipment to remanufacturer }=\text { if then else }(\text { Time }<=m, \text { MIN(Disassembly center's Inventory, } \\
\text { remanufacturer's orders backlog }) / \text { shipment time to remanufacturer, if then else (Time }>n, \\
\text { MIN(Disassembly center's Inventory, remanufacturer's orders backlog }) / \text { shipment time to } \\
\text { remanufacturer, } 0))\end{array}$ \\
\hline IV & $\begin{array}{c}\text { sales }=\text { if then else }(\text { Time }<=m, \text { MIN }(\text { Remanufacturer's Inventory, demand backlog)/delivery time, if } \\
\text { then else(Time }>n, \text { MIN }(\text { Remanufacturer's Inventory, demand backlog)/delivery time, }, 0))\end{array}$ \\
\hline
\end{tabular}

\section{Equations for four supply disruptions}

According to the definition of disruption (Wilson 2007) and the equation of supply disruption of key remanufactured parts (Gu \& Gao 2012b), in case of supply disruption I (II, III and IV), the collecting rate (shipment to DC, shipment to remanufacturer and sales) will be zero when supply disruption I (II, III and IV) occurs. The equations for collecting rate, shipment to DC, shipment to remanufacturer and sales are listed in Table 1, where $m$ and $n$ are simulation periods, $m \leq n$. The equation means that the value of the variable (collecting rate, shipment to DC, shipment to remanufacturer, sales) will be zero between the $m^{\text {th }}$ period and the $n^{\text {th }}$ period, namely, the supply disruption last for $n-m$ periods.

\section{Numerical Illustration and Simulation Analysis}

In this section, we use a numerical example to simulate supply disruption I, II, III and IV. We simulate and analyze the Mean Profit under each supply disruption, and evaluate the Impact Degree of each supply disruption. 
For each supply disruption, we use "withdisruptionj" $(\mathrm{j}=0,1, \ldots, 8)$ to denote the simulations where the supply disruption has different durations. Specifically, each simulation is run for 36 periods with $n-m$ periods disruption ( $m=10$, and $n=10,11, \ldots, 18$ ) and with the disruption starting in the $11^{\text {th }}$ period. For example, the result withdisruption0 applies to a simulation run with no disruption $(m=10, n=10)$, the result withdisruption 1 applies to a simulation run with 1 period disruption $(m=10, n=11)$, and so on.

In this numerical example, the delay time of expected demand and expected remanufacturer's orders is 1. The Minimum Value, Maximum Value, Mean, Standard Deviation and Initial Value of collection quantity are 2000, 10000, 4400, 100 and 2000 respectively. Therefore, expected demand=DELAY FIXED (demand, 1, demand); expected remanufacturer's orders=DELAY FIXED (remanufacturer's orders, 1, remanufacturer's orders ); collection quantity=RANDOM NORMAL(2000, 10000 , 4400 , $100,2000)$.

We list the values of constants used in this numerical example in Table 2.

Table 2 Values of constants for numerical illustration

\begin{tabular}{c|c|c|c|c|c}
\hline Constant & value & Constant & value & Constant & value \\
\hline $\begin{array}{c}\text { adjust time of DC's inventory } \\
\text { adjust time of remanufacturer's } \\
\text { inventory }\end{array}$ & 3 & shipment time to DC & 1 & $p 2$ & 500 \\
\hline $\begin{array}{c}\text { collecting time } \\
\text { shipment time to } \\
\text { remanufacturer }\end{array}$ & 1.5 & $t 2$ & 1.5 \\
\hline $\begin{array}{c}\text { cover time of DC's inventory } \\
\text { cover time of remanufacturer's } \\
\text { inventory }\end{array}$ & 1 & $p 0$ & 20 & $h 2$ & 15 \\
\hline $\begin{array}{c}\text { delivery time } \\
\text { demand time }\end{array}$ & 4 & $p 1$ & 5 & $b 2$ & 50 \\
\hline potential demand market & 4000 & $t 1$ & 1 & $t 3$ & 800 \\
\hline
\end{tabular}

\section{Impacts of supply disruptions on Mean Profits of supply chain members}

The Mean Profit of any member of the reverse supply chain is defined as the average profit over all the (36) simulation periods. The Mean Profits of collector, disassembly center and remanufacturer under supply disruption I, II, III and IV are shown in Figures 3, 4, 5 and 6.

Supply disruption I: All of the Mean Profits of collector, disassembly center and remanufacturer decrease when supply disruption I occur, and the decreases are increasing in the duration of the supply disruption, as expected. Only the remanufacturer maintains a positive mean profit even after an 8-period disruption, while the collector and the disassembly center experience losses when the duration of supply disruption I is equal to or longer than 5 periods (Figure 3). Supply disruption II: Similar to the case of disruption I, all Mean Profits decrease when supply disruption II occurs and the decreases are larger when the supply disruption lasts longer. However, all three members of the reverse supply chain expect to have profits even after an 8-period supply disruption of type II (Figure 4). Supply disruption III: The collector's Mean Profit decreases when the supply disruption III is longer than 3 periods, while the Mean Profits of the disassembly center and the remanufacturer decrease even if the supply disruption is brief. Again, a longer duration of supply disruption III results in lower mean profits but all members of the supply chain expect positive profits even after a long ( 8 periods) supply disruption III (Figure 5). Supply disruption IV: Only the remanufacturer's Mean Profit decreases while there is no effect on the Mean Profits of the collector and the disassembly center. The remanufacturer's Mean Profit is a decreasing function of the duration of supply disruption IV. All three members of the reverse supply chain have positive Mean Profits even if the supply disruption IV is 8 periods long (Figure 6).

The above results indicate that in the context of our numerical example only the collector and the disassembly center may face a loss and only under a supply disruption of type I and long duration. 


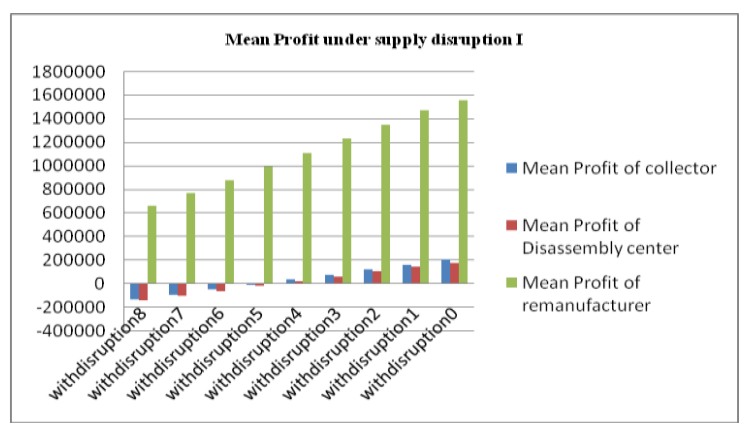

Figure 3 Mean Profits under supply disruption I

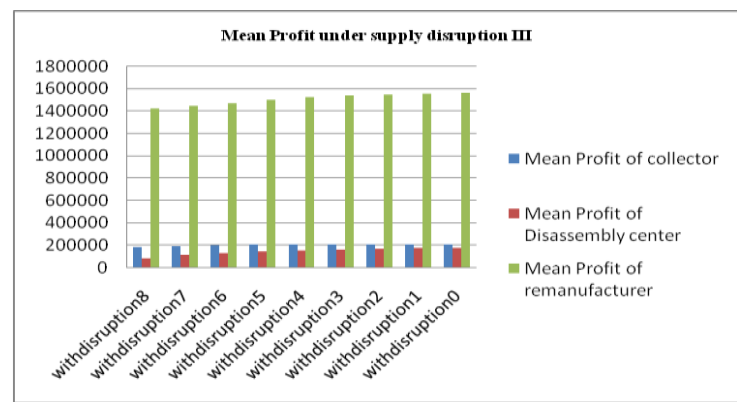

Figure 5 Mean Profits under supply disruption III

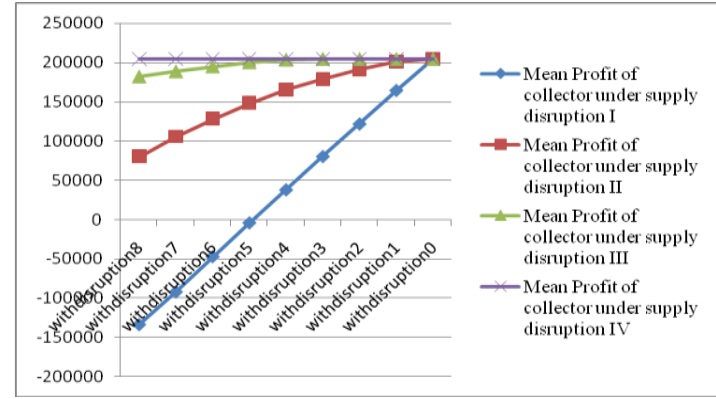

Figure 7 Impact Degree of each supply disruption on the collector

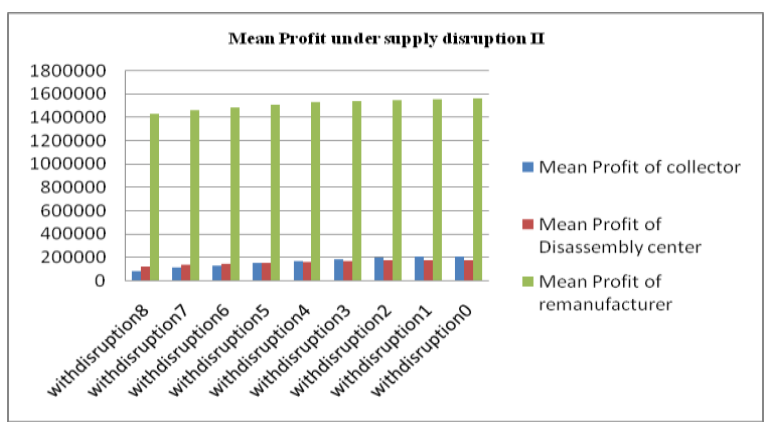

Figure 4 Mean Profits under supply disruption II

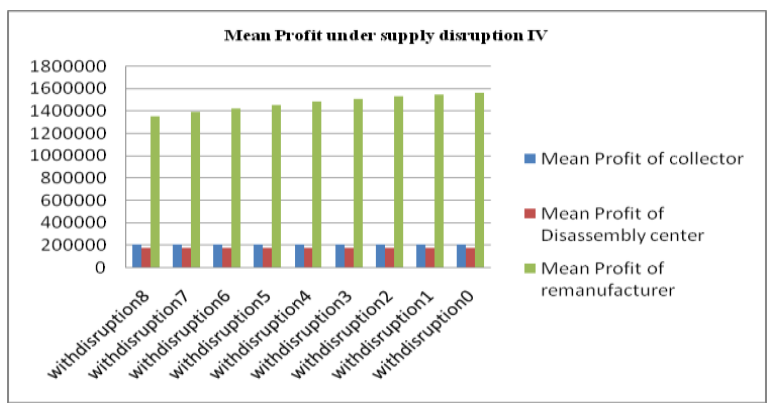

Figure 6 Mean Profits under supply disruption IV

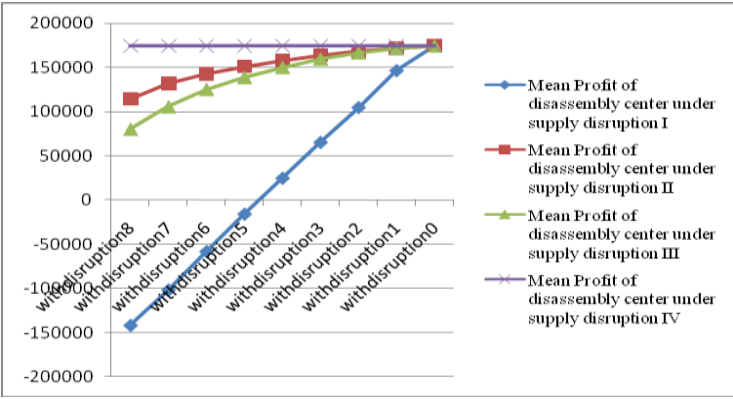

Figure 8 Impact Degree of each supply disruption on the disassembly center

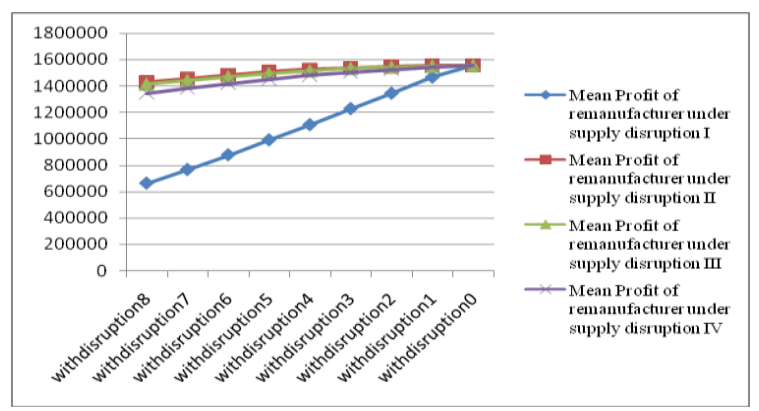

Figure 9 Impact Degree of each supply disruption on the remanufacturer

\section{Impact Degrees of four supply disruptions}

In the previous subsection we described the effects of each supply disruption on the Mean Profits of the reverse supply members. We will now propose a new quantitative measure and method for comparing more systematically the four supply disruptions. Therefore, we introduce the concept of "Impact Degree".

Impact Degree is defined as the decrease in a reverse supply chain member's Mean Profit due to a supply disruption and it is a function of the duration of the disruption. The Impact Degree of supply disruption $k(k=I, I I, I I I, I V)$ on reverse supply chain member $M(M \in\{C, D, R\})$ when supply 
disruption $k$ lasts for $i$ periods is denoted by $D_{k}^{M}(i)$. Here, $C, D$ and $R$ refer to the collector, the disassembly center and the remanufacturer respectively.

The Impact Degrees of the four supply disruptions on the collector, the disassembly center and the remanufacturer using the data of our numerical example are shown in Figures 7, 8 and 9. They have the following relationships: i) $D_{I}^{C}(i)>D_{I I}^{C}(i)>D_{I I I}^{C}(i) \geq D_{I V}^{C}(i)$ for $i=1,2,3 ; \quad D_{I}^{C}(i)>D_{I I}^{C}(i)>D_{I I I}^{C}(i)>D_{I V}^{C}(i)$ for $i=4,5, \ldots, 8$; ii) $D_{I}^{D}(i)>D_{I I I}^{D}(i)>D_{I I}^{D}(i)>D_{I V}^{D}(i)$ for $i=1,2, \ldots, 8 \quad$; iii) $\quad D_{I}^{R}(i)>D_{I V}^{R}(i)>D_{I I I}^{R}(i)>D_{I I}^{R}(i)$ for $i=1,2, \ldots, 8$.

The above results indicate that supply disruption I has the highest Impact Degree on the collector, the disassembly center and the remanufacturer, at least in a reverse supply chain with the values of Table 2 .

\section{Conclusion}

In this paper we employed system dynamics methodology to develop a simulation model that allows the study of operation and profitability of reverse supply chains with three members under four different types of possible supply disruptions. We used the model to examine a particular supply chain with specific cost and time parameters, and we found that different supply disruptions have very different impacts on the Mean profits of the reverse supply chain members. By introducing the concept of "Impact Degree", we developed a new quantitative measure and method to compare the effects of the various supply disruptions on the expected profits of the supply chain members.

\section{Acknowledgement}

This work was supported by "A Group of Five" Talent Project of the Fund of Tianjin Cultural System, the Key Advanced Research Project of Tianjin University of Technology and Education under Grant No. ZDYY1205. And the National Nature Science Foundation of China under Grant No. 70871089.

\section{References}

[1] J. Ankit, Impact of Supply Uncertainty in Supply Chain. LAP Lambert Academic Publishing AG \& Co KG. (2010).

[2] J.X.Chen, G.H.Li, G.H.Shi.,Supply Chain System Dynamics Simulation with Disruption Risks. Industrial Engineering and Management, 16(2011) 35-41.

[3] Q.L. Gu, T.G. Gao, System Dynamics Analysis of RFID/EPC's Impact on Reverse Supply Chain. 2011 International Conference on Management Science \& Engineering (18th ), (2011)250-255.

[4] Q. L. Gu, T. G. Gao, Managing Supply Disruption for Remanufacturer of Reverse Supply Chain. Proceedings of 2012 IEEE International Conference on Service Operations and Logistics, and Informatics, SOLI 2012, (2012) 331-335.

[5] M. F. Huang, M. Y. Yang, Y. K. Zhang, B.Y. Liu, System Dynamics Modeling-based Study of Contingent Sourcing under Supply Disruptions. Systems Engineering Procedia 4 (2012)290-297.

[6] H. Lorentz, O.P. Hilmola, Confidence and supply chain disruptions: Insights into managerial decision-making from the perspective of policy. Journal of Modelling in Management, 7(2012)328 - 356.

[7] Z.Q. Ma, J.X. Chen, G.H. Shi, Measurement of Supply chain disruption risks based on ARIMA model. Forecasting, 31(2012)50-56.

[8] M. C. Wilson, The impact of transportation disruptions on supply chain performance. Transportation Research Part E: Logistics and Transportation Review, 43 (2007)295-320.

[9] T.J. Yang, The impact of stock disruptions on performance of e-collaboration supply chain. Service Operations and Logistics, and Informatics, 2008. IEEE/SOLI ,2008. (2008) 1986-1990. 